\title{
Parâmetros sangüíneos e urinários, no pré e pós parto, de búfalas criadas em sistema exclusivo de pastejo ${ }^{1}$
}

\author{
Carlos Magno Chaves de Oliveira², José Diomedes Barbosa2*, Imke Barbara Pfeifer² \\ e Deugles Pinheiro Cardoso²
}

\begin{abstract}
Oliveira C.M.C., Barbosa J.D., Pfeifer I.B. \& Cardoso D.P. 2003. [The blood and urinary values in the pre and pos-parturient period of buffaloes, kept on exclusive pasture feeding.] Parâmetros sangüineos e urinários, no pré e pósparto, de búfalas criadas em sistema exclusivo de pastejo. Pesquisa Veterinária Brasileira 23(2):87-92. Central de Diagnóstico da Universidade Federal do Pará, Rua Maximino Porpino 1000, Castanhal, PA 68740-080, Brazil. E-mail: diomedes@ufpa.br

Eight lactating buffaloes of the Murrah breed were used from 60 days before up to 60 days after calving, in order to evaluate alterations in the concentration of blood glucose, total plasmatic protein, haematocrit and the presence of ketonic bodies in the urine. The 5 to 10 year old buffaloes were clinically healthy and had had at least two lactations. During the experimental period the animals were maintained on Brachiaria brizantha pasture and supplemented with a mineral mixture and water.The media concentrations of blood glucose and the media values of the haematocrit diminished significantly after calving $(p<0,05)$. The concentrations of total plasmatic protein did not show significant variation during the pre and post-calving period. The ketonic bodies in the pre-calving period were only detected in the urine of one buffaloe, but after the 32nd day of lactation ketonic bodies were detected in all animals. There was a direct relationship between the color of the urine positive by the Rothera test and blood glucose concentrations. It can be concluded that at the beginning of lactation the buffaloes had an energetic deficit, characterized by a decline of blood glucose concentrations and the presence of ketonic bodies in the urine, and that lactation caused a progressive decline of the hematocrit, but that the concentration of total plasmatic protein did not vary during the pre and post-calving period.
\end{abstract}

INDEX TERMS: Buffaloes, ketonic bodies, lactation, metabolic perfil, urine.

RESUMO.- Foi avaliada a ocorrência de alterações nas concentrações de glicose sanguínea, proteína plasmática total, hematócrito e presença de corpos cetônicos na urina de oito búfalas leiteiras da raça Murrah, com idade variando entre 5 e 10 anos, com no mínimo duas lactações, clinicamente sadias, desde 60 dias antes até 60 dias pós-parto. As concentrações médias de glicose sangüínea e o valor médio do hematócrito diminuíram significativamente no pós-parto $(p<0,05)$. As con-

\footnotetext{
${ }^{1}$ Aceito para publicação em 28 de fevereiro de 2003.

Parte da Dissertação de Mestrado, apresentada pelo primeiro autor no Curso de Pós-Graduação em Ciência Animal da Universidade Federal do Pará (UFPA), Castanhal, PA 68740-080.

${ }^{2}$ Central de Diagnóstico da UFPA, Rua Maximino Porpino 1000, Castanhal, PA 68740-080. *Autor para correspondência, e-mail: diomedes@ufpa.br
}

centrações de proteína plasmática total não sofreram variações significativas do pré para o pós-parto. No período préparto os corpos cetônicos só foram detectados na urina de uma búfala; entretanto, a partir do $32^{\circ}$ dia de lactação foram detectados em todos os animais. Houve uma relação direta entre a coloração da urina positiva para o teste de Rothera e as concentrações de glicose sangüínea. Pode-se concluir que na fase inicial da lactação as búfalas utilizadas sofreram um déficit energético, caracterizado pela diminuição nas concentrações sangüíneas de glicose e presença de corpos cetônicos na urina, e que a lactação causou um declínio progressivo no hematócrito, enquanto que as concentrações da proteína plasmática total não sofreram variações do pré para o pósparto.

TERMOS DE INDEXAÇÃO: Búfalas, corpos cetônicos, lactação, perfil metabólico, urina. 


\section{INTRODUÇÃO}

$\mathrm{Na}$ Região Norte do Brasil, o rebanho bubalino é considerado uma importante fonte econômica por possuir tripla aptidão, destacando-se na tração animal, na produção de leite e carne (Láu 1991). Por ser um animal adaptável a diversas condições ambientais, os búfalos são muito importantes para a região amazônica, uma vez que podem ser criados em áreas periodicamente inundáveis, com isso evitando ou minimizando a destruição da floresta nativa para a formação de novas pastagens.

As doenças metabólicas podem ser conceituadas como transtornos catabólicos ou anabólicos observáveis em animais em fase produtiva. A origem desses transtornos é 0 desequilíbrio entre a entrada e a saída de nutrientes do organismo, na forma de urina e fezes ou pela remoção de nutrientes na forma de produtos como o leite, a carne ou pelo feto.

Esses transtornos metabólicos geralmente atingem animais de alta produção e trazem prejuízos econômicos para a pecuária em todas as partes do mundo, pois interferem no desempenho produtivo e reprodutivo. Com os avanços no melhoramento genético para aumentar a produção, as exigências nutricionais dos animais tornaram-se maiores e em conseqüência, aumentou a incidência dos problemas relacionados com o desequilíbrio nutricional (Gonzalez 1997).

Por outro lado, existem poucos dados na literatura mundial sobre essas alterações na espécie bubalina (Patil et al. 1992). Dessa maneira, o objetivo desse estudo foi avaliar as possíveis alterações em alguns parâmetros sangüíneos e a presença de corpos cetônicos na urina, no período pré e pósparto, em búfalas criadas em sistema extensivo em pastagens de Brachiaria brizantha, no Estado do Pará.

\section{MATERIAL E MÉTODOS}

0 experimento foi realizado na Fazenda Ditosa, localizada às margens da BR-010, no Município de Ipixuna do Pará (Latitude 422' Sul; Longitude 44어' Oeste), Estado do Pará, entre os meses de agosto de 1999 e janeiro de 2000, utilizando -se oito búfalas da raça Murrah, clinicamente sadias (Quadro 1).

Os animais foram submetidos às mesmas condições de manejo, alimentados com Brachiaria brizantha e receberam sal mineral comercial, fornecido ad libitum, cuja composição era $132 \mathrm{~g} \mathrm{Na} / \mathrm{kg}, 88$ $\mathrm{g} \mathrm{P} / \mathrm{kg}, 3630 \mathrm{mg} \mathrm{Zn/kg}, 15 \mathrm{mg} \mathrm{Se} / \mathrm{kg}, 1530 \mathrm{mg} \mathrm{Cu} / \mathrm{kg}$ e 55,5 mg Co/kg.

As amostras de sangue foram colhidas de cada animal, três vezes

Quadro 1. Identificação, idade e número de lactações dos animais utilizados no experimento

\begin{tabular}{ccc}
\hline $\begin{array}{c}\text { Identificação } \\
\text { do animal }\end{array}$ & Idade (anos) & № de lactações \\
\hline 123 & 5 & 2 \\
383 & 5 & 2 \\
36 & 5 & 2 \\
73 & 5 & 3 \\
3 & 6 & 3 \\
616 & 5 & 3 \\
61 & 8 & 4 \\
100 & 9 & 6
\end{tabular}

ao dia, nos horários das 7:00, 13:00 e 17:00 horas, com intervalos de 5 dias entre as colheitas, durante um período de 60 dias antes do parto até 60 dias pós-parto. 0 sangue era colhido da veia jugular, com agulha $40 \times 16 \mathrm{~mm}$ e acondicionado em dois tubos: um contendo o anticoagulante heparina (para determinar a proteína plasmática total e o hematócrito) e outro contendo EDTA+ fluoreto de potássio, para determinar a concentração de glicose.

Para obtenção do plasma, as amostras de sangue foram centrifugadas, durante 10 minutos sob uma rotação de 4000 rpm. Em seguida, as amostras foram acondicionadas em tubos plásticos com tampa e congeladas à - 20 ㄷ C até a realização das análises.

A urina foi colhida para pesquisa de corpos cetônicos (CC), através de massagem vulvar ou micção espontânea, nos horários das 7:00 e 17:00 horas.

Logo após a colheita das amostras, os animais com suas crias, eram colocados nos piquetes localizados nas proximidades do local de retirada das amostras e eram novamente trazidos para o local de coleta, 10 minutos antes da próxima amostragem.

Para a determinação da glicose plasmática foram utilizados kits enzimáticos, que se fundamentam na reação da glicose com oxigênio e água (Kaneco 1989). A dosagem foi realizada com amostras pareadas, e a leitura feita com espectrofotômetro com filtro de 505 $\mathrm{nm}$.

Para a determinação da proteína plasmática total (PPT), foi utilizado refratômetro, que avalia a densidade do plasma como descrito por Kaneko (1989); seu valor foi expresso em g/dL.

A determinação do hematócrito foi realizada imediatamente após a colheita da manhã (7:00 horas) por meio de tubos capilares e uma centrífuga (12.000 rpm por 10 minutos) para microhematócrito.

Para a pesquisa de corpos cetônicos (CC) na urina utilizou-se 0 Teste de Rothera (Rosenberger 1983). Foram consideradas positivas as amostras que apresentavam coloração violácea e os resultados expressos, subjetivamente, em + (coloração fraca),++ (coloração média), + + + (coloração forte).

Os dados das variáveis estudadas foram tabulados no programa Microsoft Excel e analisados utilizando-se a análise de variância e 0 teste de Tukey. As médias foram consideradas como similares quando $p<0,05$.

\section{RESULTADOS E DISCUSSÃO}

Embora se tenha sido observada uma diminuição significativa $(p<0,05)$ nos níveis médios da glicose do pré para o pósparto (Quadro 2), esses valores são superiores aos 55 a 60mg/ dL citados por Zicarelli et al. (1982) como referência para vacas búfalas em lactação. Esses menores valores, encontrados por esses autores, podem ser devido à maior produção leiteira das vacas búfalas utilizadas naquele estudo.

A diminuição nos valores da glicose sangüínea do pré para o pós-parto foi similar à descrita por Quayam et al. (1990) e Setia et al. (1992), muito embora os valores encontrados por

Quadro 2. Valores médios e desvios padrões da glicose sangüínea nos períodos pré e pós-parto em oito búfalas da raça Murrah

\begin{tabular}{ccc}
\hline Períodos & Glicose $(\mathrm{mg} / \mathrm{dL})$ & Desvio padrão \\
\hline Pré-parto & $66,6^{\mathrm{a}^{*}}$ & 9,66 \\
Pós-parto & $65,2^{\mathrm{b}}$ & 8,92
\end{tabular}

*Letras minúsculas diferentes entre linhas significam que os valores são estatisticamente diferentes $(p<0,05)$. 


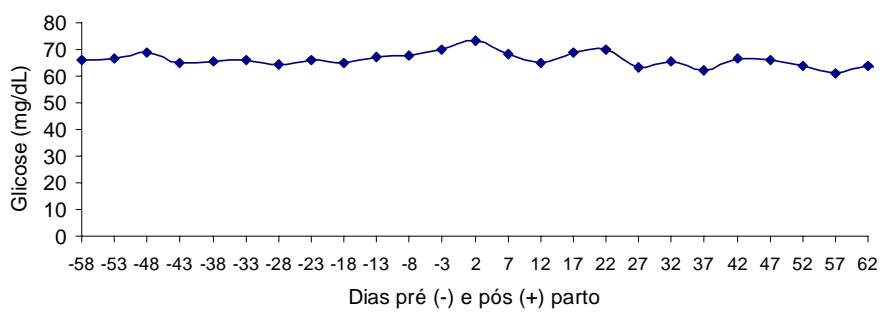

Fig. 1. Valores médios diários de glicose sanguínea nos períodos pré e pós-parto em oito búfalas da raça Murrah.

esses autores sejam bem inferiores, tanto no período pré, quanto no pós-parto, aos encontrados neste trabalho. A diminuição nos valores da glicose sangüínea do pré para o pósparto, segundo Bergman (1983), deve-se principalmente à exigência de glicose pela glândula mamária para a produção da lactose, a qual consome cerca de 60 a 85\%da glicose corporal total em vacas bovinas de alta produção. Todavia estes achados diferem dos encontrados por Fagliari et al. (1998), que encontraram no pós-parto um valor de glicose maior do que no pré-parto, tanto em vacas búfalas quanto em bovinas. Tal aumento, provavelmente, tenha ocorrido em função da alimentação rica em carboidratos não estruturais utilizados para 0 arraçoamento daqueles animais.

Foi constatado um pequeno aumento da glicose sangüínea em torno de uma semana antes do parto (Fig. 1). Essa elevação da glicemia pode ser devida aos hormônios glicocorticóides liberados pelo estresse do parto eminente (Gonzalez 1997). Fagliari et al. (1998), trabalhando com vacas bovinas e bubalinas, não observaram esse aumento na glicemia nesse mesmo período.

Também foi verificado um aumento significativo $(p<0,05)$ na concentração sangüínea de glicose do horário das 7:00 para as 17:00 horas (Quadro 3). Wittwer (2000), por outro lado, afirma que as concentrações de glicose sangüínea não sofrem variações significativas durante o dia. Barbosa (1996), da mesma forma, não encontrou variações na glicose sangüínea durante 0 dia em vacas da raça holandesa que receberam infusões, ora com glicose no rúmen, ora com glicose ou caseína no abomaso.

Uma provável explicação para o aumento da glicemia do período da manhã para a tarde é o aumento dos ácidos graxos

Quadro 3. Valores médios e desvios padrões da glicose sangüínea (mg/dL) em diferentes horários, nos períodos pré e pós-parto em oito búfalas da raça Murrah

\begin{tabular}{|c|c|c|c|c|c|c|}
\hline \multirow[t]{3}{*}{ Períodos } & \multicolumn{6}{|c|}{ Glicose (mg/dL) } \\
\hline & \multicolumn{2}{|c|}{$7: 00 \mathrm{~h}$} & \multicolumn{2}{|c|}{$13: 00 \mathrm{~h}$} & \multicolumn{2}{|c|}{$17: 00 \mathrm{~h}$} \\
\hline & Média & $\begin{array}{l}\text { Desvio } \\
\text { Padrão }\end{array}$ & Média & $\begin{array}{l}\text { Desvio } \\
\text { Padrão }\end{array}$ & Média & $\begin{array}{l}\text { Desvio } \\
\text { Padrão }\end{array}$ \\
\hline Pré & $64,7^{a A^{*}}$ & 10,0 & $66,5^{\mathrm{abA}}$ & 9,36 & $68,5^{b A}$ & 9,40 \\
\hline Pós-parto & $64,8^{\mathrm{aA}}$ & 8,45 & $65,2^{\mathrm{abB}}$ & 9,34 & $65,7^{\mathrm{bB}}$ & 9,06 \\
\hline
\end{tabular}

*Médias seguidas de mesmas letras, minúsculas ou maiúsculas, nas linhas ou nas colunas, não são estatisticamente diferentes $(p<0,05)$. voláteis no rúmen, especialmente o propiônico, algumas horas após os períodos de alimentação (Dirksen et al. 1993). Essa glicose, poderia, também, estar aumentada devido ao estresse causado aos animais pelo manejo a que eram submetidos durante os dias de colheita de sangue. Com 0 estresse, os níveis de cortisol aumentam no sangue e, com isso, desencadeiam os processos gliconeogênicos principalmente a partir das proteínas musculares (Aires 1999), que, segundo Schultz (1974), podem ser responsáveis pela formação de aproximadamente 15 a $25 \%$ da glicose corporal total.

Ao relacionarmos a concentração média de glicose no sangue com a idade e o número de lactações dos animais (Quadro 4), constatamos que as búfalas (de números $61 \mathrm{e}$ 100) que têm 8 e 10 anos de idade e 4 e 6 lactações, respecti-

Quadro 4. Relação dos valores médios de glicose sanguínea nos períodos pré e pós-parto com a idade e o número de lactações em oito búfalas da raça Murrah

\begin{tabular}{|c|c|c|c|c|c|c|}
\hline \multirow{3}{*}{$\begin{array}{c}\text { Animal } \\
\text { no. }\end{array}$} & \multicolumn{4}{|c|}{ Glicose (mg/dL) } & \multirow{3}{*}{$\begin{array}{l}\text { Idade } \\
\text { (anos) }\end{array}$} & \multirow{3}{*}{$\begin{array}{c}\text { № de } \\
\text { lactações }\end{array}$} \\
\hline & \multicolumn{2}{|c|}{ Pré-parto } & \multicolumn{2}{|c|}{ Pós-parto } & & \\
\hline & Média & $\begin{array}{l}\text { Desvio } \\
\text { padrão }\end{array}$ & Média & $\begin{array}{l}\text { Desvio } \\
\text { padrão }\end{array}$ & & \\
\hline 123 & 77,3 & 8,84 & 71,8 & 7,06 & 5 & 2 \\
\hline 383 & 72,8 & 7,54 & 70,5 & 9,93 & 4 & 2 \\
\hline 036 & 65,6 & 5,27 & 64,7 & 8,31 & 4 & 2 \\
\hline 73 & 72,3 & 5,92 & 68,2 & 9,39 & 5 & 3 \\
\hline 3 & 65,6 & 6,43 & 65,6 & 5,77 & 6 & 3 \\
\hline 616 & 65,4 & 5,81 & 64,6 & 4,86 & 5 & 3 \\
\hline 61 & 59,9 & 8,48 & 62,6 & 7,58 & 8 & 4 \\
\hline 100 & 54,2 & 4,63 & 54,5 & 5,49 & 9 & 6 \\
\hline
\end{tabular}

vamente, apresentaram os menores valores de glicose, tanto no pré quanto no pós-parto quando comparados com os demais. A causa poderia ser os sucessivos danos causados ao fígado em virtude da mobilização de gordura dos tecidos a cada lactação para suprir a falta de energia causada pela produção de leite (Sommer 1975). Esses achados são semelhantes aos observados por Rautmare et al. (1989) e Balakishan \& Rao (1994), os quais encontraram um balanço energético negativo em búfalas com idades que variaram de 6 a 9 anos, o que foi verificado pelo maior aparecimento de CC na urina.

Com exceção da Búfala 61, nenhum outro animal apresentou corpos cetônicos (CC) na urina no período pré-parto, ou pelo menos em quantidades suficientes para que pudessem ser detectados pelo teste de Rothera. No pós-parto todos os animais apresentaram pelo menos uma vez, reação positiva para CC na urina, as quais foram mais freqüentes a partir do $32^{\circ}$ dia do puerpério (Quadro 5).

A maior freqüência de aparecimento dos CC na urina a partir do $32^{\circ}$ dia de lactação foi também relatada por Schultz (1974), Dohoo \& Martin (1984), Dohoo et al. (1984) e Grohn et al. (1984), os quais afirmam que tanto a cetose clínica como a sub-clínica ocorrem geralmente durante as 8 primeiras semanas após o parto. Outros autores relacionaram a presença de CC na urina de búfalas com o estágio da lactação e encontraram 56,4 \%(Rautmare et al. 1989), e 28,3\%(Balakishan \& 
Quadro 5. Evidência de corpos cetônicos, em diferentes dias no pós-parto, em amostras de urina obtidas nos horários das 7:00 e 17:00 h em oito búfalas da raça Murrah

\begin{tabular}{|c|c|c|c|c|c|c|c|c|c|}
\hline \multirow{2}{*}{\multicolumn{2}{|c|}{$\begin{array}{c}\text { Dias } \\
\text { pós-parto }\end{array}$}} & \multicolumn{8}{|c|}{ Búfalas } \\
\hline & & 100 & 123 & 061 & 383 & 073 & 036 & 003 & 616 \\
\hline \multirow[t]{2}{*}{2} & $7 \mathrm{~h}$ & $+a$ & & & & & & & \\
\hline & $17 \mathrm{~h}$ & + & & & & & & & \\
\hline 29 & $7 \mathrm{~h}$ & & & & & & & & + \\
\hline \multirow[t]{2}{*}{32} & $7 \mathrm{~h}$ & ++ & & & & & & & \\
\hline & $17 \mathrm{~h}$ & ++ & & & & & & & \\
\hline 33 & $7 \mathrm{~h}$ & & & & & & & + & \\
\hline \multirow[t]{2}{*}{35} & $7 \mathrm{~h}$ & & ++ & & & & & & \\
\hline & $17 \mathrm{~h}$ & & ++ & & & & & & \\
\hline 37 & $7 \mathrm{~h}$ & + & & & & & & & \\
\hline 38 & $7 \mathrm{~h}$ & & & & & & + & & \\
\hline 43 & $7 \mathrm{~h}$ & & & & & & ++ & & \\
\hline 47 & $7 \mathrm{~h}$ & + & & & & & & & \\
\hline 48 & $7 \mathrm{~h}$ & & & & & & +++ & & \\
\hline 49 & $7 \mathrm{~h}$ & & & ++ & & & & & \\
\hline 51 & $7 \mathrm{~h}$ & & & & ++ & & & & \\
\hline 53 & $7 \mathrm{~h}$ & & & & & +++ & + & & \\
\hline 56 & $7 \mathrm{~h}$ & & & & + & & & & \\
\hline
\end{tabular}

a+ Coloração fraca, + + coloração média, ++ + coloração forte.

Rao 1994) dos casos de cetose utilizando o teste de Rothera no primeiro e segundo mês de lactação.

Quando comparamos o período ( $32^{\circ}$ dia de lactação) a partir do qual houve um maior aparecimento de CC na urina das búfalas com as concentrações médias de glicose sangüínea (Fig. 1), percebemos que o declínio nas concentrações de glicose ocorreu a partir do $32^{\circ}$ dia de lactação, coincidindo assim com o maior aparecimento de CC na urina. Esses achados também foram descritos por Schultz (1974), Dohoo \& Martin (1984), Dohoo et al. (1984) e Grohn et al. (1984).

Embora todos os animais tenham apresentado CC na urina, não foi observada a manifestação clínica da cetose como descrita por diversos autores (Rosenberger 1983, Riet-Correa et al. 1998).

Também foi observado que o maior aparecimento desses CC se deu a partir do início de dezembro (Quadro 6), correspondendo ao início da estação chuvosa na região e, por conseqüência, ao início da brotação das pastagens, que possuem nesse estágio vegetativo, baixos teores de matéria seca. 0 menor consumo de matéria seca tem como conseqüência uma menor ingestão de carboidratos solúveis, o que resultará em pequena produção de ácido propiônico pelas bactérias ruminais e, com isso, uma menor produção de glicose a partir da gliconeogênese.

Foi constatado que houve uma relação direta entre a intensidade da coloração da urina dos animais que apresenta-

Quadro 6. Relação entre os meses do ano e o aparecimento de cetose sub-clínica no pós-parto em oito búfalas da raça Murrah

\begin{tabular}{ccc}
\hline Meses & Casos de cetose & $\%$ \\
\hline Novembro & 2 & 12,5 \\
Dezembro & 8 & 100
\end{tabular}

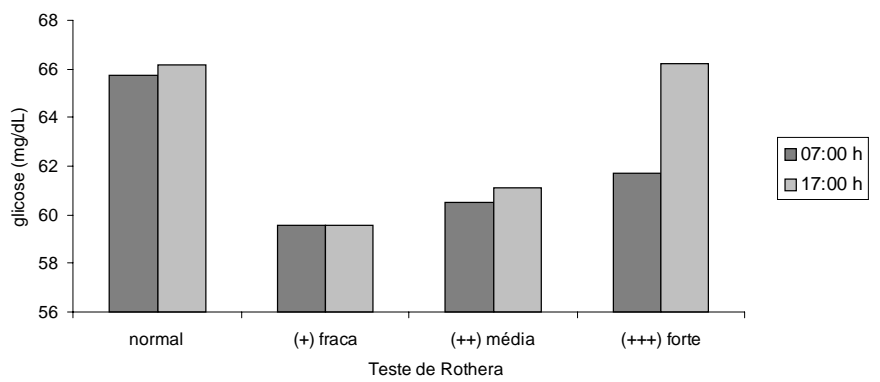

Fig. 2. Comparação dos valores obtidos para a glicose sangüínea com o grau de intensidade de corpos cetônicos na urina detectados pelo teste de Rothera.

ram cetose sub-clínica e os valores de glicose no sangue, uma vez que os animais que apresentaram uma coloração fraca, apresentaram menor concentração de glicose no sangue do que os animais de coloração média e coloração forte (Fig. 2). Uma possível explicação para esse fato seria que os níveis baixos de glicose estimulariam de forma mais intensa a gliconeogênese a partir das outras fontes alternativas como o glicogênio, os aminoácidos gliconeogênicos, o glicerol e 0 lactato, através da ação dos hormônios como o glucagon, 0 hormônio do crescimento, a epinefrina e o cortisol (Bergman 1983, Van der Walt \& Linington 1989, Kaneko 1989, Wittwer 2000). Com isso elevaria a glicemia sem causar uma diminuição dos CC. A permanência elevada deste metabólito ocorre devido a uma diminuição nas concentrações do oxaloacetato, que é formado a partir do propionato durante a gliconeogênese, fazendo com que a acetil-CoA que e derivada da degradação da gordura seja desviada para a formação de CC (Bergman 1983, Rosenberger 1983).

A proteína plasmática total não teve variação significativa $(p<0,05)$ do pré para o pós-parto (Quadro 7). Dados similares foram encontrados por Setia et al. (1992), em vacas búfalas, entretanto em vacas bovinas observaram um aumento significativo nas concentrações plasmáticas da proteína total com 0 avanço da lactação. Koval (1971), também observou esse aumento na concentração da PPT nos primeiros quatro meses de lactação de vacas bovinas e seu declínio no final da mesma. Esse aumento na PPT observado por esses autores, provavelmente seja devido a uma alimentação de melhor qualidade oferecida para os animais no pós-parto, uma vez

Quadro 7. Valores médios da Proteína Plasmática Total (g/dL) em diferentes horários, nos períodos pré e pós-parto em oito búfalas da raça Murrah

\begin{tabular}{|c|c|c|c|c|c|c|c|}
\hline \multirow[t]{3}{*}{ Períodos } & \multicolumn{6}{|c|}{ Proteína plasmática total $(\mathrm{g} / \mathrm{dL})$} & \multirow{3}{*}{$\begin{array}{l}\text { Média } \\
\text { Geral }\end{array}$} \\
\hline & \multicolumn{2}{|c|}{$7: 00 \mathrm{~h}$} & \multicolumn{2}{|c|}{$13: 00 \mathrm{~h}$} & \multicolumn{2}{|c|}{$17: 00 \mathrm{~h}$} & \\
\hline & Média* & $\begin{array}{l}\text { Desvio } \\
\text { padrão }\end{array}$ & Média & $\begin{array}{l}\text { Desvio } \\
\text { padrão }\end{array}$ & Média & $\begin{array}{l}\text { Desvio } \\
\text { padrão }\end{array}$ & \\
\hline & & 0,5 & & 0,5 & $8,62^{a}$ & 0,53 & \\
\hline Pós-parto & $8,83^{a}$ & 0,50 & $8,66^{\mathrm{a}}$ & 0,42 & $8,71^{\mathrm{a}}$ & 0,46 & $8,73 \pm 0,46$ \\
\hline
\end{tabular}

*Letras minúsculas iguais nas linhas e colunas significam que os valores não diferem estatisticamente $(p<0,05)$. 


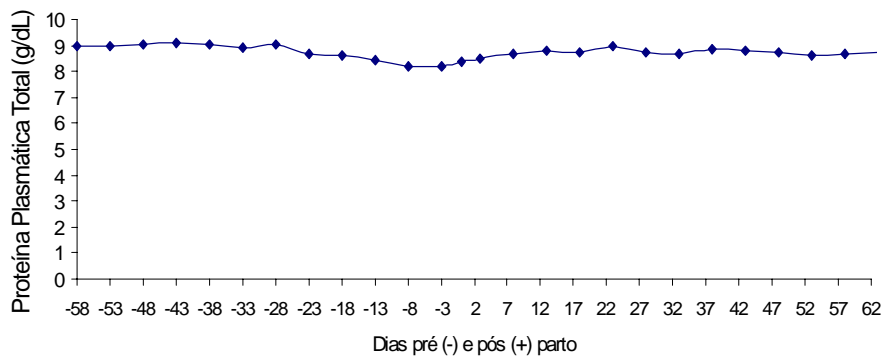

Fig. 3. Valores médios da proteína plasmática total $(\mathrm{g} / \mathrm{dL})$ nos períodos pré e pós-parto em oito búfalas da raça Murrah.

que para Manik et al. (1988), as concentrações de PPT estão relacionadas diretamente com as concentrações de proteína e energia da alimentação.

Foi observado também que houve uma diminuição da PPT poucos dias antes do parto e seu retorno ao normal logo após o mesmo (Fig. 3). Esses achados corroboram com os de Rowlands et al. (1975), Quayam et al. (1990) e Fagliari et al. (1998), que encontraram em vacas bovinas e bubalinas uma diminuição não significativa na PPT nas ultimas semanas de gestação. Isso segundo Mulei (1991) é causado principalmente pela transferência de imunoglobulinas do plasma para 0 colostro. Para Gonzalez (1997), a diminuição da PPT nesse período pode ser de 10 a 20\%da concentração normal, recuperando-se logo em seguida.

Os valores médios da PPT variaram de 8,86 a $8,73 \mathrm{~g} / \mathrm{dL}$, não sendo encontradas variações significativas durante o dia (Quadro 7). Esses valores são superiores aos encontrados por Salem et al. (1984). Kulkarni \& Talvelkar (1984) e Singla \& Sharma (1992), os quais determinaram a concentração de PPT no sangue de búfalas lactantes encontrando valores que variaram de 5,35 até $8,47 \mathrm{~g} / \mathrm{dL}$. Ao relacionarem esses valores com a estação de parição, mês de lactação, estágios reprodutivos, produção de leite e número de lactações, concluíram que não houve variações significativas.

Neste experimento foi detectada uma diminuição significativa $(p<0,05)$ no hematócrito dos animais no período pósparto (Fig. 4). Estes achados são similares os verificados por Samak et al. (1981), que também encontraram uma diminuição significativa do hematócrito no pós-parto, principalmente no início e meio da lactação de vacas bovinas. Para Rowlands et al. (1975) e Jones et al. (1982), a produção de leite no pós-parto seria o fator responsável pela diminuição

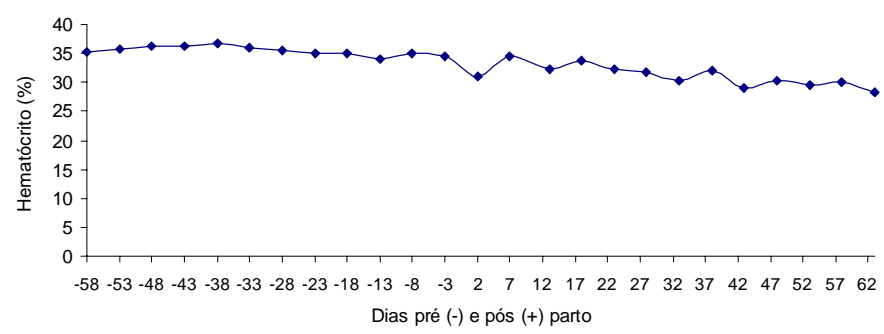

rig. 4. vaiores meaios aiarios de nematocrito nos perioaos pre e pós-parto em oito búfalas da raça Murrah. do hematócrito. Porém, Dirksen et al. (1993), afirmam que os fatores nutricionais, como a deficiência de proteínas e minerais (ferro, cobre e cobalto) são as principais fatores responsáveis pela diminuição do hematócrito em vacas bovinas em lactação no pós-parto.

\section{CONCLUSÕES}

- Ocorrem alterações metabólicas promovidas pela lactação em búfalas criadas em pastagens de Brachiaria brizantha, caracterizadas por diminuição nas concentrações de glicose sangüínea e aumento dos corpos cetônicos na urina no início da lactação.

- Em 83,3\%dos casos a cetose sub-clínica foi encontrada no horário das 7:00 horas.

- Os valores médios da glicose sangüínea sofreram variações significativas durante 0 dia, tanto no pré quanto no pós-parto, caracterizada por um aumento em seus valores do horário das 7:00 para as 17:00 horas.

- Os valores médios da proteína plasmática total não sofreram variações significativas do pré para o pós-parto e nem durante o dia.

- Os valores médios da glicose e da proteína plasmática total nos períodos pré e pós-parto foram $66,6 \pm 9,66 \mathrm{e}$ $65,2 \pm 8,92(\mathrm{mg} / \mathrm{dL})$ e $8,76 \pm 0,54$ e $8,73 \pm 0,46(\mathrm{~g} / \mathrm{dL})$, respectivamente.

- A lactação causou uma diminuição significativa no hematócrito de todas as búfalas em estudo.

- Houve uma relação direta entre as concentrações médias de glicose e a presença de corpos cetônicos na urina.

\section{REFERÊNCIAS}

Aires M.M. 1999. Fisiologia. $2^{\text {a }}$ ed. Guanabara Koogan, Rio de Janeiro. 934 p. Balakishan T. \& Rao D.S.T.1994. Sub-clinical ketosis in buffaloes. Cheiron 23(5): 200-204.

Barbosa J.D.1996. Untersuchungen zur Wirkung von Pansen- und Labmageninfusionen mit Glucose und Casein auf die Milchleistung und den Intermediärstoffwechsel von Milchkühen. Tese de Doutorado, Hannover, Alemanha. 97p.

Bergman E. N. 1983. The pools of cellular nutrients: glucose, p. 173-196. In: Riis P.M. Dynamic Biochemistry of Animal Production. Elsevier, New York.

Dirksen G., Gründer H.D. \& Stöber M. 1993. Exame Clínico dos Bovinos. Rio de Janeiro. 419p.

Dohoo I.R. \& Martin S.W. 1984. Sub-clinical ketosis: prevalence and associations with production and disease. Canadian J. Comp. Medicine 48:15.

Dohoo I.R., Martin S.W., M cMillan I. \& Kennedy B.W. 1984. Disease, production and culling in Holstein-Friesian cows. II. Age, season and sire effects. Preventive Vet. Medicine 2: 665-670.

Fagliari J.J., Santana A.E. , Marchió W., Campos Filho E. \& Curi P.R. 1998. Constituintes sangüíneos de vacas das raças Nelore (Bos indicus) e Holandesa (Bos taurus) e de bubalinas (Bubalus bubalis) da raça Murrah durante a gestação, no dia do parto e no puerpério. Arq. Bras. Med. Vet. Zootec. 50(3):273-282.

Gonzalez F.H.D. 1997. O perfil metabólico no estudo de doenças da produção em vacas leiteiras. Arqs Fac. Veterinária. UFRGS, Porto Alegre, 25(2):1364.

Grohn Y., Thompson J.R. \& Bruss M.L. 1984. Epidemiology and genetic basis of ketosis in Finnish Ayrshire cattle. Preventive Vet.Medicine 3:65-77. 
Jones G.M., Wildman E.E. \& Troutt H.F. 1982. Metabolic perfiles in Virginia dairy herds of different milk yields. J. Dairy Sci. 65:683-688.

Kaneko J.J. 1989. Clinical Biochemistry of Domestic Animals. $4^{\text {th }}$ ed. Academic Press, San Diego, California. 932p.

Koval S.S.1971. Lactation change in blood serum protein and its fractions in Simmental cows. Nauchnya Zapiski Belstseerkovskogo Selsko Khozyaistvennogo Institut 21:20-23.

Kulkarni B.A. \& Talvelkar B.A. 1984. Studies on serum biochemical constituents lactating and dry indian buffaloes. Indian Vet. J. 61:564-568.

Láu H.D. 1991. Manual de práticas sanitárias para bubalinos jovens. Circular Técnico 60, Embrapa-CPATU, Belém, PA. 36p.

Manik R.S., Srivastava A. \& Mudgal V.D. 1988. Significance of season influenced changes in haematology of murrah buffaloes fed varying levels of dietary protein. Indian J. Anim. Prod. 4(1):22-26

Mulei C.M. 1991. Changes in blood chemistry in late pregnancy and early lactation and their relationships to milk production in dairy cows. Bull.Anim.HIth Prod.Afr. 39:77-119.

Patil M.D., Talvelkar B.A., Joshi V.G. \& Deshmukh B.T. 1992. Haematological studies in murrah buffaloes. Indian Vet. J. 69:661-663.

Quayam S.A., Devanathan T.G. \& Pattabiraman S.R. 1990. Serum total protein and blood glucose levels during pre-, peri- and post-partum Murrah buffaloes. Indian J. Anim Sci. 60(2):140-142.

Rautmare S.S., Anantwar L.G. \& Singh B. P. 1989. Prevalence of ketosis in buffaloes (Bubalus bubalis). Indian J. Vet. Med. 9(1):2

Riet-Correa F., Schild A.L. \& Méndez M.C. 1998. Doenças de Ruminantes e Eqüinos. Pelotas, Rio Grande do Sul. 653p.

Rosenberger G. 1983. Enfermedades de los Bovinos. Tomo II. Hemisferio Sur. 577 p.

Rossow N. \& Bolduan G. 1994. Stoffwechsel-Störungen bei Haustieren. Gustav Fischer Verlag, Jena.

Rowlands G.J., Mantson R., Rita M.P. \& Sally M.D. 1975. Relationships between stage of lactation and pregnancy and blood composition in a herd of dairy cows and the influence of seasonal changes in managements on these relationships. J. Dairy Res. 42:349-362.

Salem I.A., Allam F.M., Darwish A.H. \& Daghach H.A.1984. Effect of calving season on values of total serum protein and its fractions during lactation period of Friesian cows and buffaloes in upper Egypt. Assiut. Vet. J..12(23):37-44.

Samak M., Hassan A. \& Elezz Z.A. 1981. Relationship between blood haematocrit and haemoglobin levels with lactational performance of dairy animals under different physiological conditions. Indian J.Dairy Sci. 34(2):165-170

Schultz L.H. 1974. Ketosis, p. 317-353. In: Larson B.L. \& Smith V.R. (ed.) Lactation, a Comprehensive Treatise. Vol. 2. Academic Press, New York.

Setia M.S., Duggal R.S. \& Singh R. 1992. Biochemical constituints of blood in buffaloes and cows during late pregnancy and different stages of lactation - a longitudinal study. Buffalo J. 2:123-129.

Singla V.K. \& Sharma R.D.1992. Profiles of some serum biochemical constituents before and after parturition in buffaloes. Indian Vet. J. 69:565566.

Sommer H.1975. Preventive medicine in dairy cows. Vet. Med. Rev. 1:42-63.

Van der Walt J.G. \& Linington M.J. 1989. A review of energy in producing ruminants, part 1: Metabolism of energy substrates. J. S. Afr. Vet. Assoc. 60(4):223-227.

Wittwer F. 2000. Diagnóstico dos desequilíbrios metabólicos de energia em rebanhos bovinos, p. 9-22. In: González F.H.D., Barcellos J.O., Ospina H. \& Ribeiro L.A.O. (ed.) Perfil Metabólico em Ruminantes: seu Uso em Nutrição e Doenças Nutricionais. Gráfica da Universidade Federal do Rio Grande do Sul, Porto Alegre.

Zicarelli L., Intrieri F., Franciscis G. \& Squillaciotti S. 1982. Profilo metabolico nella bufala gravida in relazione al regime alimentare adottato. , p.262288. In: Indagine in Allevamenticon Diversa Incidenza di Prolasso Vaginali. Atti II Conv. Int. Sullallevamento Bufalino nel Mondo, v.1. Napoli, Itália. 